\title{
PATOLOGIAS EM INSTALAÇÕES HIDROSSANITÁRIAS NOS EDIFÍCIOS DA UFV
}

\author{
SOUZA, LUIZ PAULO FONSECA \\ Estudante \\ Universidade Federal de Viçosa \\ MG; Brasil \\ luiz.p.souza@ufv.br
}

\author{
SILVA, REGINALDO CARNEIRO DA \\ Professor Associado \\ Universidade Federal de Viçosa \\ MG; Brasil \\ recsilva@ufv.br
}

\section{RESUMO}

Como importante subsistema de uma edificação as instalações hidrossanitárias devem funcionar adequadamente. A falta de uma cultura de manutenção preventiva e preditiva em edificações, em especial edifícios públicos, e de um retorno aos projetistas e executores dessas obras sobre patologias nesses sistemas, torna o conhecimento sobre suas ocorrências e causas escasso, principalmente porque essas podem ocorrer longo tempo após a conclusão das obras. Com isso, o presente trabalho teve como objetivo analisar manifestações patológicas nos sistemas hidrossanitários dos prédios institucionais da UFV, a fim de gerar recomendações para projetos e obras futuros. Foram examinadas ordens de serviço de manutenção, realizadas investigações junto a bombeiros hidráulicos da universidade e visitas aos locais afetados. Por fim, foram gerados gráficos, frutos das análises, apresentados registros fotográficos e feitas sugestões para procedimentos de projeto, execução e manutenção desses sistemas.

Palavras-chave: Sistema hidrossanitário. Patologias hidrossanitárias. Edifícios públicos.

\section{ABSTRACT}

The hydro-sanitary installations must be work properly. The lack of a culture of preventive and predictive maintenance in edifications, especially public ones, and feedback for the designers and builders about pathologies in these systems, make knowledge about the occurrences and causes scarce, mainly because those can occur a long time after the conclusion of the building. Thereby, the present work had the objective of analyze pathological manifestations in the hydro-sanitary systems of UFV institutional buildings and to generate recommendations for projects and future constructions. Orders of service were examined, were also made investigations with plumbers and site visits. Lastly, were generated graphics product of those analysis, made photographic records and the suggestions for future projects, construction and maintenance of this systems.

Keywords: Hydro-sanitary system. Hydro-sanitary pathologies. Public buildings.

\section{INTRODUÇÃO}

As edificações são sistemas complexos compostas por diversos subsistemas como o estrutural, elétrico, vedações entre outros. Desses sistemas, o hidrossanitário é um dos que os usuários mais interagem. Por sua vez, patologias em edificações são definidas como a falta de atendimento aos requisitos de desempenho e funcionalidades exigidos por normas, legislações e/ou contratos estabelecidos com o construtor e a falta de atendimento às expectativas dos usuários (GNIPPER e MIKALDO JR., 2019) (ABNT, 2013). As patologias em sistemas hidrossanitários, em especial, causam grandes transtornos aos usuários, além de estarem intimamente ligados à sua saúde e higiene.

Historicamente, não se dá o devido cuidado às instalações hidráulicas e sanitárias nas construções, quer seja no projeto, ou falta dele, e nas etapas de construção e manutenção. $\mathrm{O}$ avanço das tecnologias construtivas e a concorrência no setor de construção, além de preocupações com questões ambientais e escassez de recursos, têm levado ao aprimoramento dos projetos e métodos construtivos. O aumento da difusão no uso de modelos de informação da construção (BIM) tem evitado erros de compatibilidade de projetos, retrabalhos e gastos desnecessários de materiais, causando assim maior qualidade e menos patologias nestes serviços (DOLABELA; FERNANDES, 2014). 
No âmbito do pós-obra, a falta de uma cultura no Brasil de manutenções preventivas e preditivas, juntamente com a falta de acompanhamento do desempenho destes sistemas implica na ocorrência de patologias causadas por usos e desgastes não previstos. A implantação e utilização de sistemas de manutenção programada em edificações, antes que apresentem problemas, se mostra vantajoso tanto economicamente quanto do ponto de vista do conforto de utilização do usuário (MACEDO, 2015).

Os estudos de manifeatações patológicas em sistemas hidrossanitários, de modo geral, são escassos dado que estes demandam grandes períodos para uma observação detalhada e completa. Desde o período de projeto até o possível surgimento de problemas nesses sistemas podem se passar vários anos (GNIPPER, 2011). Isso também causa uma lacuna de informação para construtores e projetistas, visto que estes não recebem ou recebem tardiamente, retorno sobre soluções e materiais adotados em construções anteriores que não satisfizeram suas expectativas de qualidade. Ademais, não é incomum que se executem estas instalações de forma diferente do projetado, devido a erros de interpretação de projeto e/ou problemas encontrados na execução, isso mostra a importância da realização de projetos representativos da obra finalizada, conhecidos como As Built, principalmente em grandes edificações comerciais e institucionais, facilitando assim as futuras manutenções.

Com isso, pretende-se com esse trabalho, contribuir com a Universidade Federal de Viçosa (UFV) através da catalogação das manifestações patológicas hidrossanitárias mais comuns em alguns edifícios da instituição, a identificação de suas causas e sugestão de formas de evitá-las. Espera-se, assim, que os mesmos erros não sejam cometidos em construções futuras evitando diversos incômodos, interrupções de funcionamento, prejuízos econômicos e ambientais além de melhorar a qualidade da interação dos usuários com os sistemas hidráulicos e sanitários prediais.

\section{IMPORTÂNCIA DO ESTUDO DAS PATOLOGIAS}

De acordo com a NBR 15575 (ABNT, 2013), a falta de desempenho de uma edificação ocorre quando há a percepção por parte do usuário ou proprietário que esta não atende as expectativas feitas na venda ou construção do empreendimento.

Falhas em qualquer das etapas de construção de qualquer sistema, em especial os sistemas hidrossanitários, incorrem em prejuízos econômicos com retrabalhos e manutenções que podem chegar a valores de grande monta. Um exemplo de uma dessas falhas é a falta de compatibilidade entre projetos que geram adaptações não recomendadas em obras que, quase sempre, incorrem em problemas futuros (DOLABELA; FERNANDES, 2014). Além disso, a existência de patologias nesses sistemas como também manutenções frequentes e instalações não adequadas geram insatisfações aos usuários destes edifícios, como avaliado através de diversas pesquisas de pós ocupação, caracterizando a falta de desempenho destas.

Problemas decorrentes de sistemas hidrossanitários podem causar ou agravar patologias em outros sistemas prediais, como por exemplo, um vazamento de tubulação de água atingir o sistema elétrico predial ou ocasionarem corrosão de armaduras em sistemas estruturais de concreto armado. Ademais, o conhecimento das patologias auxilia na criação de programas e documentações de manutenção preventiva, que consiste em uma técnica em que a manutenção é realizada no período adequado, antes que ocorra uma falha qualquer (GNIPPER, 2011), evitando os transtorno e custo das manutenções corretivas.

Deve ser considerado também, que estudos sobre patologias em sistemas hidrossanitários podem ser custosos e demandar grandes períodos de observação, o que faz com que informações nesta área não sejam tão abundantes, bem como a diversidade de suas possíveis causas.

\section{DESENVOLVIMENTO}

\subsection{Unidades avaliadas}

O presente trabalho analisou edifícios do campus Viçosa da Universidade Federal de Viçosa. O campus conta com 484.322,69 $\mathrm{m}^{2}$ de área construída com edifícios com as mais diversas finalidades como: bibliotecas, alojamento, restaurantes, salas de aulas, gabinetes de professores, laboratórios de pesquisa, entre outros, os quais atendem a mais de 18.000 pessoas entre alunos, servidores e professores. 
Os edifícios foram escolhidos com auxílios da Diretoria de Manutenção de Edificações (DIM) da Universidade, afim de formarem uma amostra representativa baseado no fluxo de pessoas e conhecimentos prévios dos históricos de manutenção destes. Os edifícios analisados foram:

-Pavilhão de Aulas I (PVA);

-Pavilhão de Aulas II (PVB);

-Centro de Vivência;

-Hospital Veterinário;

-Alojamento Velho;

-Alojamento Novo;

-Alojamento Novíssimo;

-Alojamento Pós;

-Alojamento Posinho;

-Alojamento Feminino.

\subsection{Manifestações patológicas}

A investigação das patologias se deu em três momentos: Análise das ordens de serviço obtidas com a Diretoria de Manutenção de Edificações (DIM) da Universidade, investigação junto aos bombeiros hidráulicos da UFV e visita a alguns dos locais analisados. As ordens de serviço foram gentilmente fornecidas pela DIM através do sistema próprio da universidade de cadastro e controle de ordens de serviço, o SisDIM.

As ordens de serviço foram analisadas se eram solicitações relacionadas a patologias ou outros tipos, sendo excluída as que não remetiam a patologias, como solicitações de materiais. As patologias foram então classificadas entre os sistemas utilizando as seguintes siglas:

AF - Água Fria;

AQ - Água Quente;

AP - Águas Pluviais;

ES - Esgoto Sanitário;

NI - Não Identificado.

Em seguida, as ordens de serviço de cada sistema foram contabilizadas por tipo de problema como vazamentos, entupimentos, etc., afim de se estabelecer qual destas era a mais crítica. Além de algumas das ordens não estarem relacionadas a patologias, outras apresentam solicitações de mais de um sistema simultaneamente. Com isso, foram gerados os gráficos e análises que se encontram nos resultados. Ao todo foram analisadas 587 ordens de serviço que datam desde novembro de 2004 até 19 de agosto de 2019, dia em que os dados foram coletados.

Com base na análise das ordens de serviço foi elaborado um roteiro para investigação junto aos bombeiros hidráulicos que fazem as manutenções e instalações no campus, qual a percepção de quais as principais patologias que estes lidam, quais as causas e soluções mais comuns, dificuldades de realização dos reparos, recebimento de feedback dos serviços, entre outros aspectos que poderiam auxiliar nas análises.

Por fim, alguns dos lugares analisados e citados pelos bombeiros hidráulicos foram visitados afim de se confirmar ou verificar a existência de algumas das patologias e realizar o registro fotográfico destas.

\section{RESULTADOS E DISCUSSÕES}

\subsection{Resultado das investigações junto aos bombeiros hidráulicos}

A Diretoria de Manutenção da UFV, vinculada à Pró-Reitoria de Administração, conta com 6 bombeiros hidráulicos, sendo um deles o encarregado. Foi realizada uma investigação junto a estes profissionais. Representados pelo encarregado José Mauro Costa da Silva, servidor da universidade na Diretoria de Manutenção de Edificações, com 40 anos de experiência na profissão sendo a maior parte nesta instituição. 
Primeiramente foi reportado pelo bombeiro que os sistemas onde mais se realizam manutenções são em água fria e esgoto sanitário. Já quanto as edificações, as que na percepção dele, apresentam mais patologias são os pavilhões de aula (PVA e PVB) e prédio com laboratórios como o Departamento de Tecnologia de Alimentos (DTA).

Quanto as patologias por sistema, este mencionou que as principais em água fria são vazamento em descargas, válvulas de mictório e engates de lavatórios. Já em esgoto sanitário predominam entupimentos de pias e mictórios. Em água quente vazamentos no geral e água pluvial quase não apresenta problemas. As soluções adotadas consistem de substituição de peças e encanamentos defeituosos e, para os entupimentos, a passagem de sondas, utilização de ácido muriático e as vezes, a depender da gravidade do entupimento, a demolição de parte da tubulação.

Com relação as causas, o bombeiro cita que a maior parte, na sua percepção, é causada por desgaste das instalações e mau uso com o descarte, por exemplo, de bitucas de cigarro em pias, produtos químicos que causam incrustação em esgoto de laboratórios, absorventes em vasos sanitários, entre outros. Como foi observado um grande número de ordens de serviço sobre entupimentos de mictórios e vasos sanitários, questionou-se sobre estes sendo apontado como principal causa de entupimento de vasos sanitários o mau uso e de mictórios os próprios sólidos presentes na urina que se incrustam na tubulação, aliado ao pequeno diâmetro da própria saída da louça e a frequente falta de descarga deste aparelho por parte dos usuários.

Além destas considerações feitas, foram feitas observações sobre: objetos que não deveriam ser descartados no sistema de esgoto que causaram entupimentos como pedaços de pano, palhas de aço e absorventes; instalações/projetos executadas de forma errônea como no Colégio de Aplicação (Coluni) onde existe apenas uma válvula de descarga para vários mictórios e esta ainda fica distante destes, como mostra a Figura 1. Foi ainda apresentado uma sugestão para novas instalações pelo bombeiro José Mauro, consistindo no uso de mictórios coletivos do tipo calha, com divisórias e reaproveitamento da água proveniente do esgoto da pia para sua descarga.

Figura 1 - Banheiro masculino do Coluni.

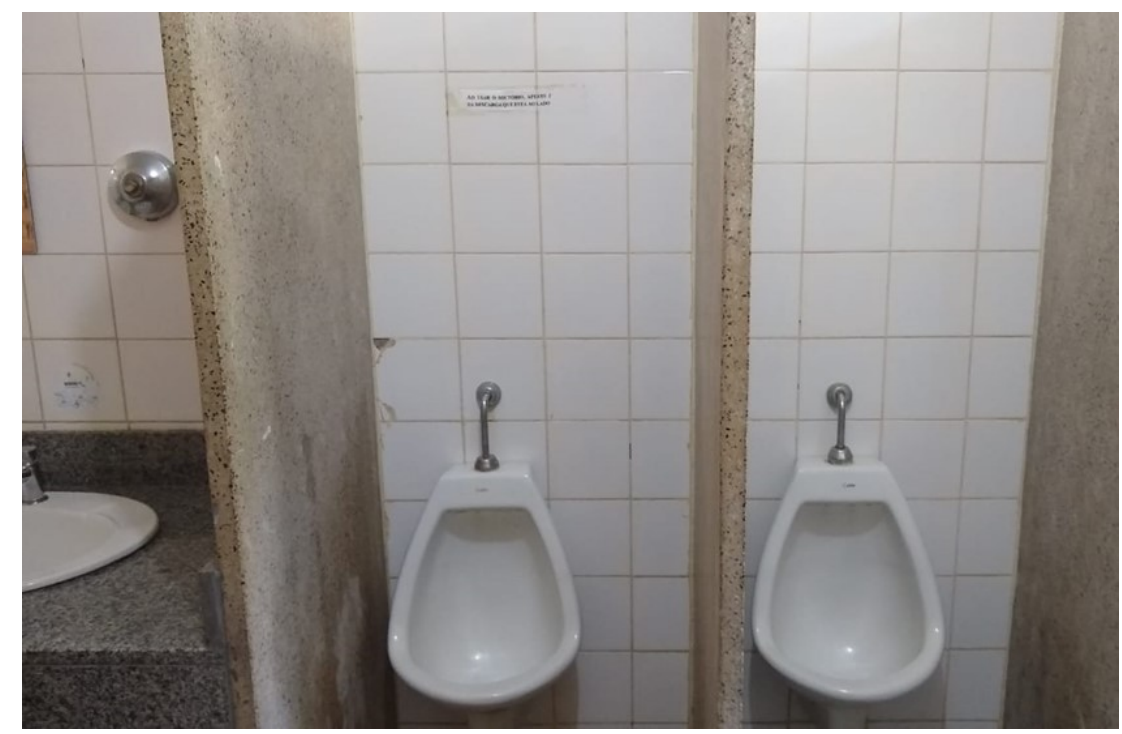

Fonte: os autores

\subsection{Análise das ordens de serviço}

As ordens de serviço foram analisadas uma a uma afim de se identificar os principais tipos de solicitações e em que sistema ocorrem. Como as ordens são mensagens não padronizadas foi realizada leitura e separação através de filtros afim de realizar a contabilidade destas através de palavras chaves.

Um resumo das principais solicitações nas ordens de serviço é apresentado na Tabela 1, onde são assinaladas as patologias encontradas em cada edifício sendo as células preenchidas representando as patologias mais frequentes nos respectivos edifícios. 
Tabela 1 - Resumo das patologias indicadas nas ordens de serviço

\begin{tabular}{|c|c|c|c|c|c|c|c|c|c|c|c|}
\hline \multirow[t]{3}{*}{ Sist. } & \multirow[t]{3}{*}{ Patologia } & \multicolumn{2}{|c|}{ Edifício } & \multirow{3}{*}{$\begin{array}{l}\text { Centro de } \\
\text { Vivência }\end{array}$} & \multirow{3}{*}{\begin{tabular}{|c|}
$\begin{array}{c}\text { Hospital } \\
\text { Veteriná } \\
\text { rio }\end{array}$ \\
\\
\end{tabular}} & & & \multirow[b]{3}{*}{$\begin{array}{c}\text { Novíss } \\
\text { imo }\end{array}$} & \multirow[b]{3}{*}{$\begin{array}{c}\text { Femini } \\
\text { no }\end{array}$} & \multirow[b]{3}{*}{ Pós } & \multirow[b]{3}{*}{$\begin{array}{c}\text { Posinh } \\
0\end{array}$} \\
\hline & & PVA & PVB & & & \multicolumn{2}{|c|}{ Alojamentos } & & & & \\
\hline & & & & & & Velho & Novo & & & & \\
\hline \multirow[t]{6}{*}{ AF } & Vazamento no bebedouro & & $\mathrm{x}$ & $x$ & & & & & & & \\
\hline & $\begin{array}{c}\text { Vazamento - Descarga/Válvula } \\
\text { mictório }\end{array}$ & $\bar{x}$ & $x$ & $x$ & & & $x$ & $x$ & $x$ & $\mathrm{X}$ & $\bar{x}$ \\
\hline & Vazamento - Torneira/Registro & $x$ & $x$ & $x$ & $x$ & & $x$ & & $x$ & $x$ & \\
\hline & Vazamento - Tubulação & $\mathrm{x}$ & & $\mathrm{x}$ & & $\mathrm{x}$ & & & $\mathrm{x}$ & & \\
\hline & Falta d'água/perda de pressão & & $x$ & $\mathrm{x}$ & $\mathrm{x}$ & $x$ & & $x$ & $\mathrm{x}$ & & $x$ \\
\hline & Peça danificada & & $\mathrm{X}$ & $\mathrm{X}$ & & $\mathrm{X}$ & $\mathrm{x}$ & $\mathrm{X}$ & $\mathrm{X}$ & $\mathrm{x}$ & $\mathrm{X}$ \\
\hline \multirow[t]{5}{*}{ ES } & Entupimento - Vaso Sanitário & $x$ & $x$ & $\bar{x}$ & & & $\mathrm{x}$ & $x$ & & $x$ & $x$ \\
\hline & Entupimento - Mictório & $\mathrm{x}$ & $\bar{x}$ & $\mathrm{x}$ & & & & & & & \\
\hline & Entupimento - Pia/Ralo & & & $\mathrm{X}$ & $x$ & & $\mathrm{x}$ & $x$ & $x$ & $x$ & $\mathrm{x}$ \\
\hline & Peça danificada & $x$ & & $\mathrm{x}$ & & & $\mathrm{x}$ & $x$ & $\mathrm{x}$ & & $x$ \\
\hline & Vazamento & $\mathrm{X}$ & $x$ & $\mathrm{X}$ & $\mathrm{x}$ & $x$ & $\mathrm{X}$ & & $\mathrm{X}$ & $\bar{x}$ & $x$ \\
\hline \multirow[t]{3}{*}{$A Q$} & Aquecimento deficiente & & & & & $x$ & & & & & \\
\hline & Vazamento & & & & & $x$ & & & $x$ & $\mathrm{x}$ & \\
\hline & Falta d'água/perda de pressão & & & & & & & & $\mathrm{x}$ & & \\
\hline
\end{tabular}

Fonte: os autores

Como é possível constatar da Tabela 1, não foram encontradas solicitações que se refiram ao sistema de águas pluviais, o que foi confirmado posteriormente em investigações junto aos bombeiros hidráulicos. Após a análise criteriosa de cada uma das solicitações identificadas como patologias, a separação destas por tipo de sistema resultou no gráfico apresentado na Figura 2.

Figura 2 - Patologias por sistema na UFV

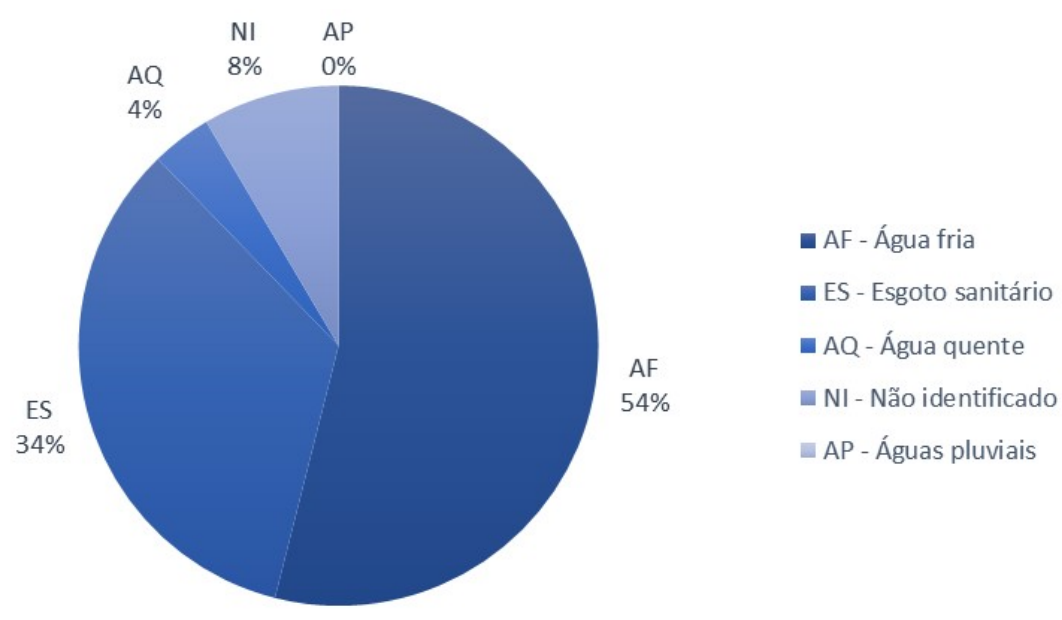

Fonte: os autores 
Na Figura 3 indica-se o número de patologias encontradas nas ordens de serviço, bem como os percentuais relativos ao número total de patologias encontradas, separadas por edifício analisado. Ao todo foram identificadas 482 patologias.

Figura 3 - Número de patologias por edifício na UFV.

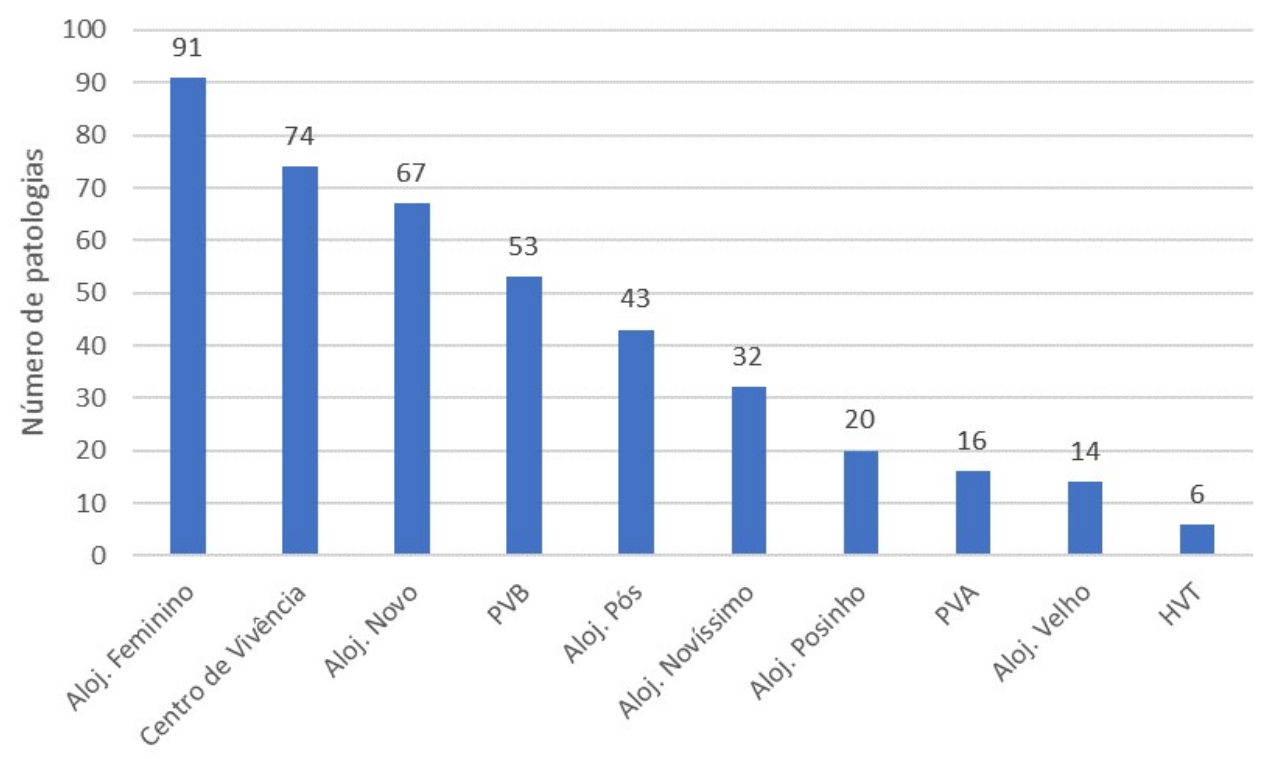

Fonte: os autores

\subsection{Patologias encontradas}

Nas visitas a algumas das instalações hidrossanitárias dos edifícios analisados puderam ser observadas algumas manifestações patológicas, estas foram registradas fotograficamente e são apresentadas a seguir.

A Figura 4 mostra o banheiro masculino do primeiro pavimento do PVB com um mictório interditado e um mictório ausente, danificado durante tentativa de desentupimento.

Figura 4 - Banheiro do PVB.

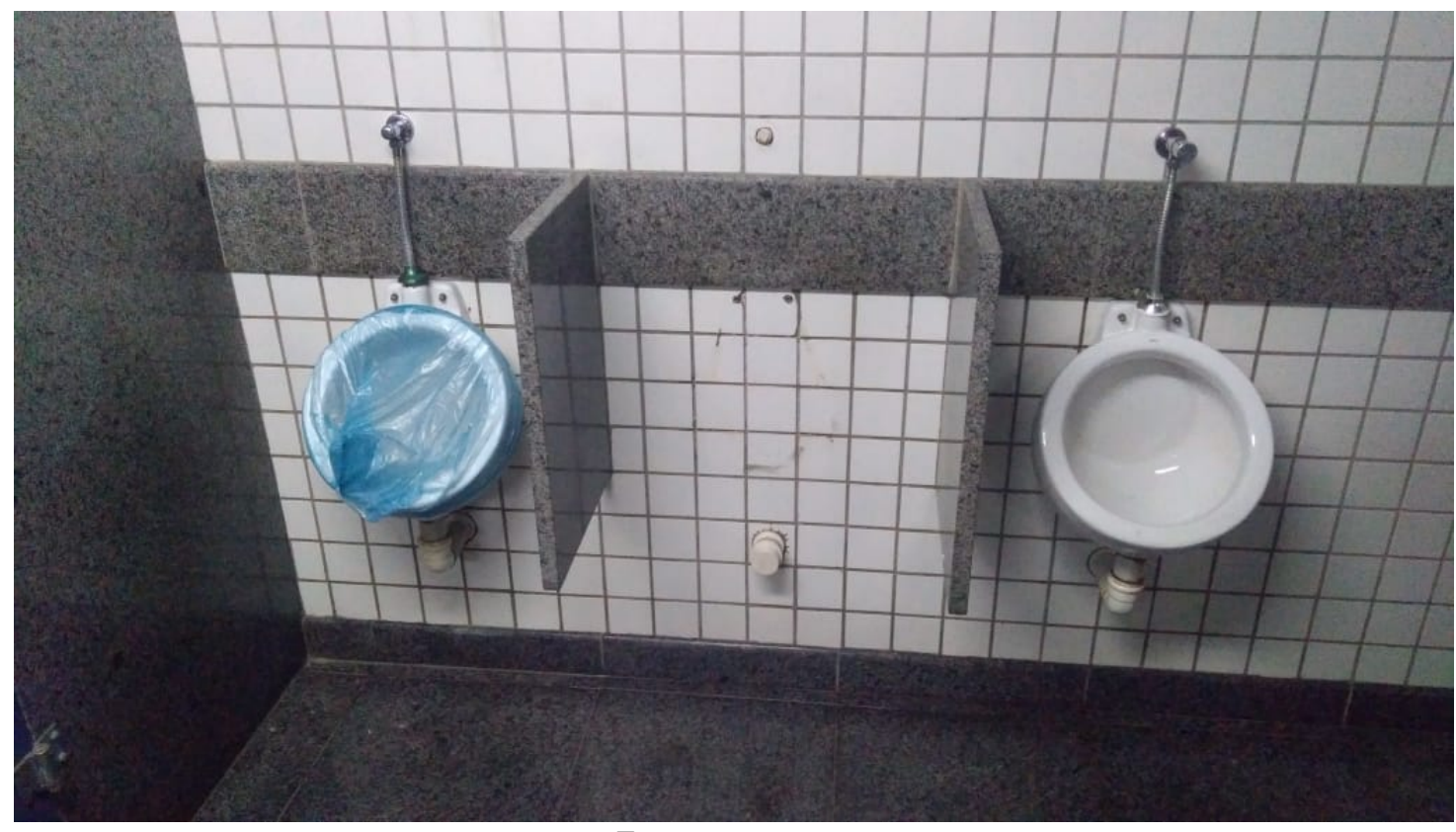

Fonte: os autores 


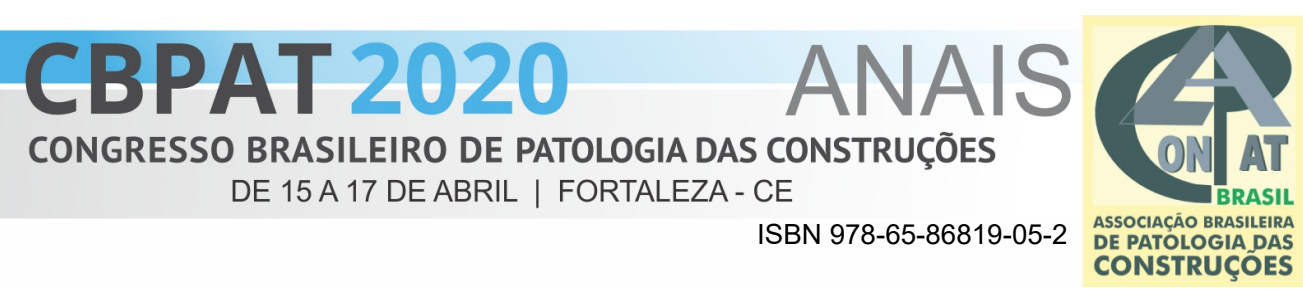

A Figura 5 apresenta o bebedouro do primeiro andar do PVA com entupimento.

Figura 5 - Bebedouro do PVA.

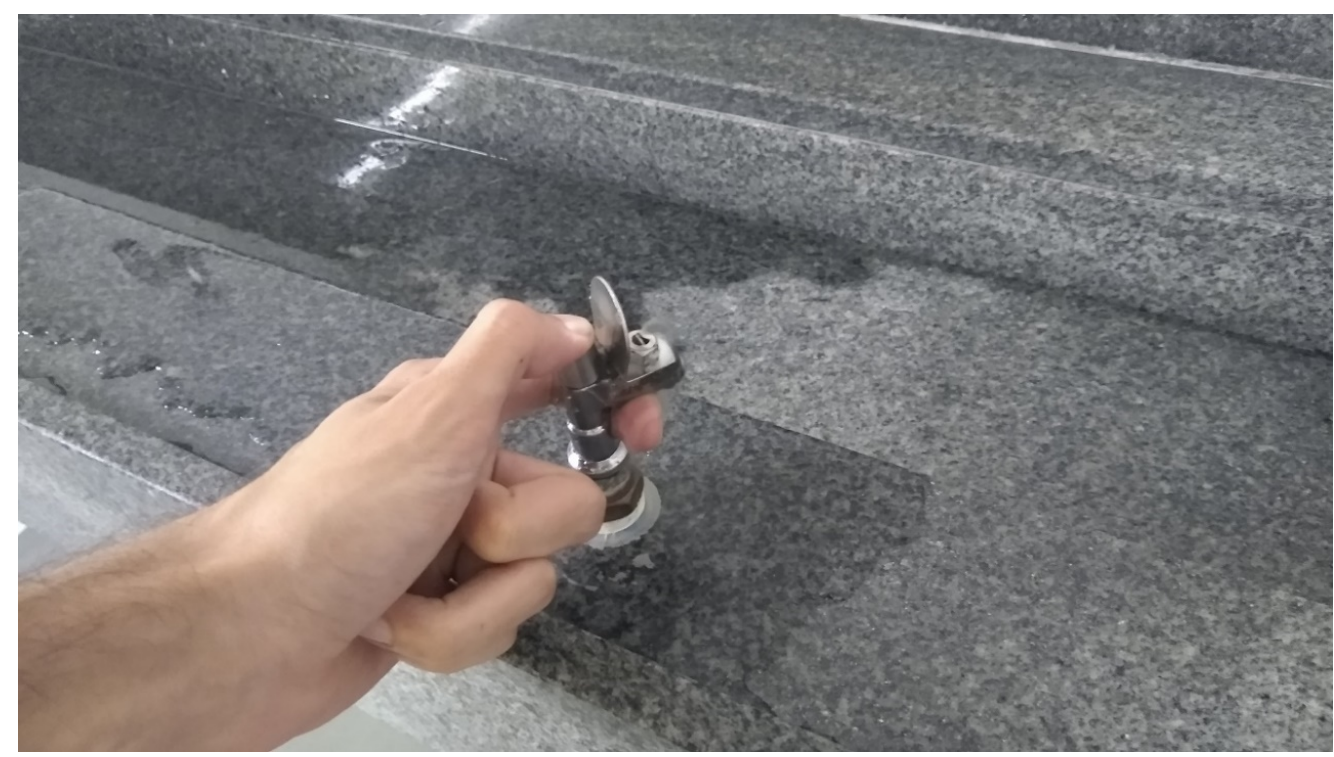

Fonte: os autores

A Figura 6 indica a pintura do teto danificado por antiga infiltração no banheiro do apartamento 116 do alojamento feminino possivelmente causada por patologia hidrossanitária ou de impermeabilização

Figura 6 - Infiltração em banheiro do alojamento feminino.

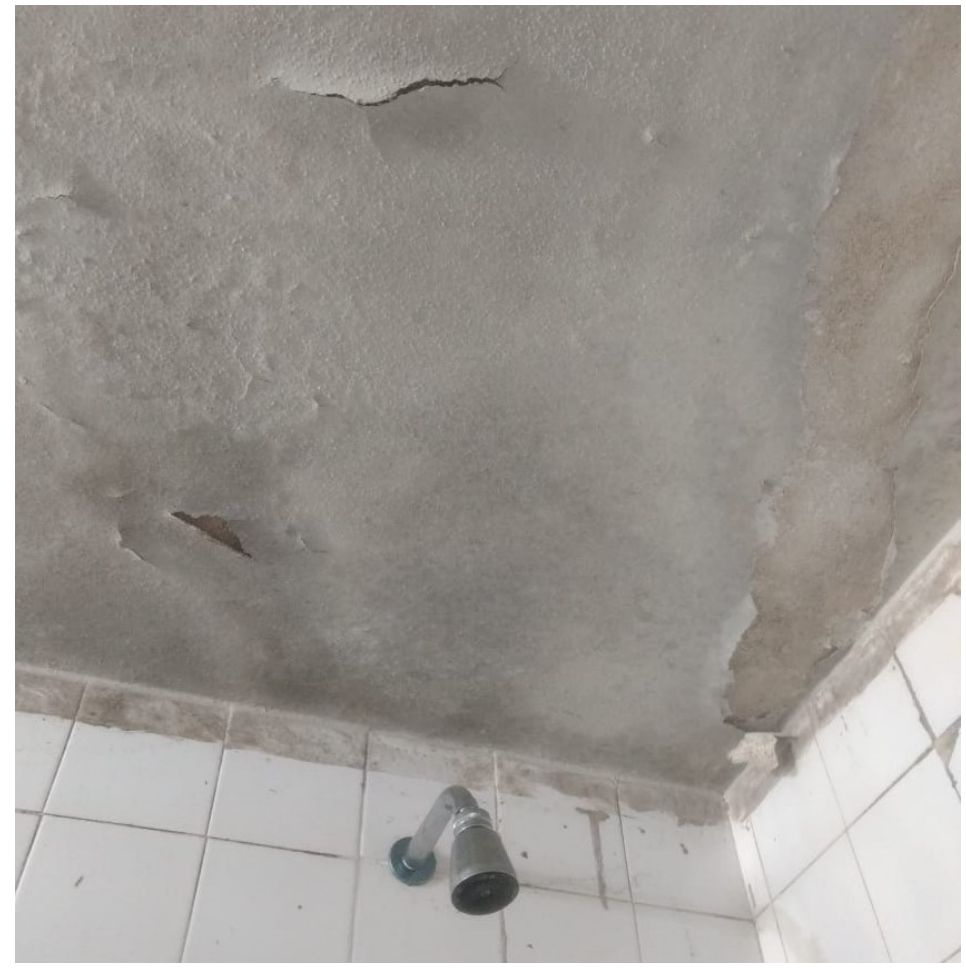

Fonte: os autores

A Figura 7 mostra a louça da pia danificada no banheiro do subsolo do centro de vivência. 


\section{СВРAT 2020 \\ concerss o ans \\ DE 15 A 17 DE ABRIL | FORTALEZA - CE}

Figura 7 - Louça da pia do banheiro do centro de vivência

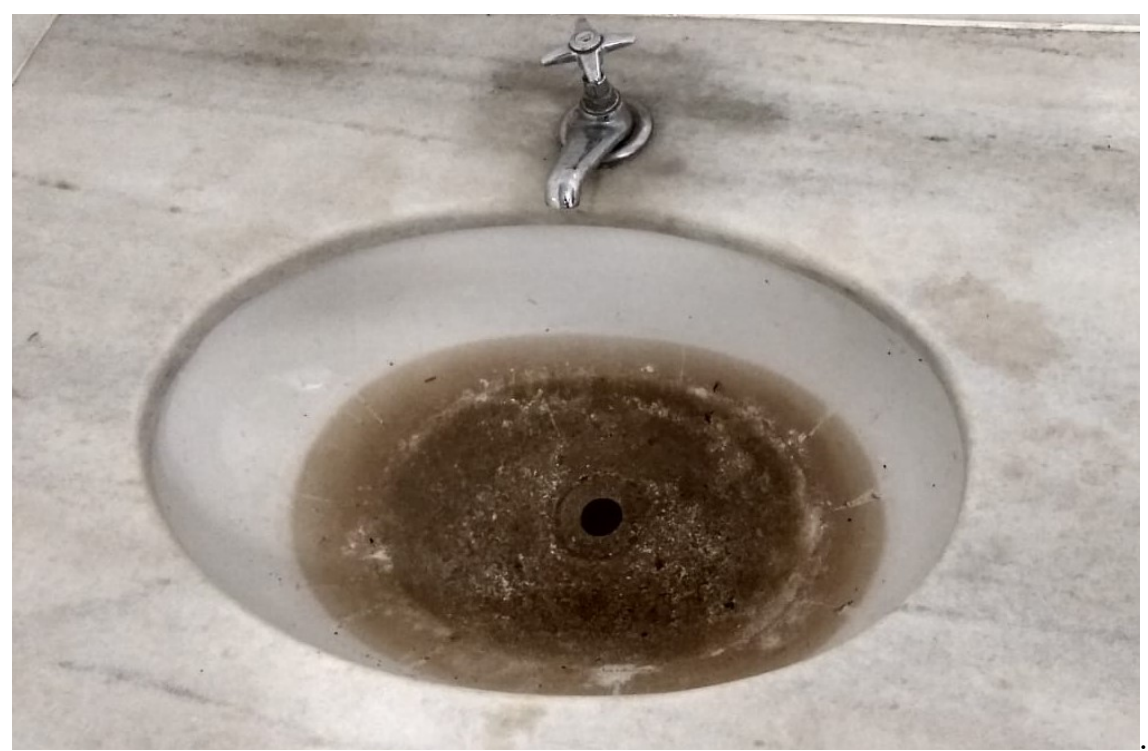

Fonte: os autores

A Figura 8 indica as instalações de torneira improvisadas na pia do banheiro do subsolo do centro de vivência.

Figura 8 - Torneiras improvisadas no banheiro do centro de vivência.

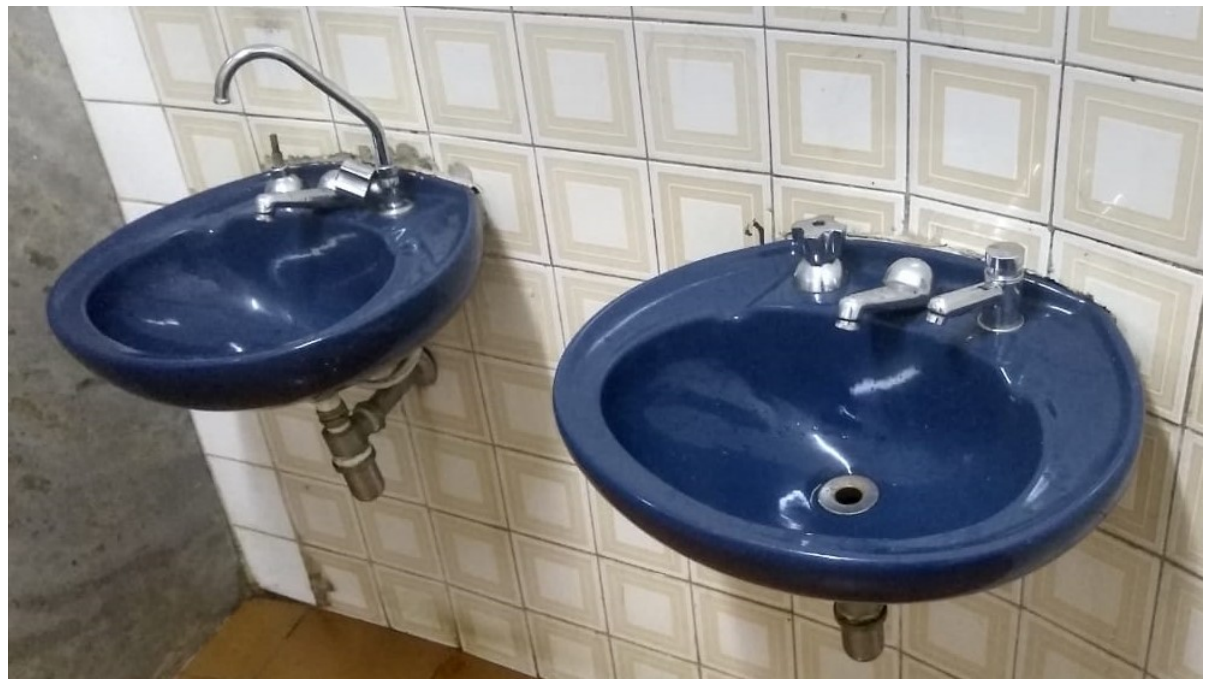

Fonte: os autores

\subsection{Discussões e recomendações}

Com base na análise dos dados e visitas realizadas, algumas propostas de ações a serem tomadas em futuras construções e reformas foram feitas e estão listadas abaixo.

- Implementação de avisos quanto ao descarte irregular de objetos como absorventes e bitucas em vasos sanitários e pias, em especial nos banheiros coletivos de grande fluxo de pessoas como PVA e PVB;

- Emprego da tecnologia de modelagem da informação da construção (BIM) no projeto e manutenção de novas edificações; 
- Capacitação dos profissionais responsáveis pelas solicitações de ordens de serviço afim de facilitar a comunicação correta e padronização das ocorrências;

- Utilização de mictórios coletivos do tipo calha com divisórias, pois incorrem em menor custo de instalação, atendendo ao mesmo número de pessoas e demandam menos manutenção, como ressaltado pelo bombeiro José Mauro, conjugados com reaproveitamento de água dos lavatórios como descarga;

- Importância da padronização dos materiais utilizados e sua disponibilidade em almoxarifado para que os serviços de manutenção e reparo sejam mais rápidos;

- Em algumas situações, deve-se utilizar instalações aparentes que também facilitam a manutenção;

- Adoção de política de manutenção preventiva e inspeções periódicas nas instalações das edificações, afim de prevenir os prejuízos materiais ou não com o surgimento destas patologias;

- Registro digital das ações corretivas tomadas de modo que possam ser analisados posteriormente e a eficiência das manutenções e seus respectivos tempos de resposta, como recomenda a ABNT NBR 5674.

\section{CONCLUSÃO}

O presente trabalho analisou a ocorrência de manifestações patológicas em edifícios da UFV possibilitando um maior entendimento de quais são e onde ocorrem tais patologias. O resultado das análises e visitas demonstrou que a maior parte das patologias em prédios de grande fluxo de pessoas se referem a entupimentos de mictórios, e nos alojamentos a problemas de entupimentos, registros e válvulas de descarga.

A maior parte das patologias analisadas se referem a problemas causados por mau uso e desgaste das instalações, diferente do constatado em outros trabalhos que indicam que a maior parte das causas é proveniente de erros de projeto e execução. Uma possível explicação é que, como os edifícios analisados são públicos, necessariamente existem projetos e fiscalização da execução destes sistemas, o que nem sempre se encontra em obras privadas.

Não foram verificadas relações diretas entre o número de patologias e a idade dos edifícios ou fluxo de pessoas. As manifestações patológicas dependem da combinação desses e de outros fatores como periodicidade de reformas e manutenções, sendo complexa sua análise. Por fim, foram feitas as recomendações para projetos e execuções futuras, ressaltando-se a necessidade de manutenções preventivas de modo a evitar prejuízos e incômodo aos usuários das edificações.

\section{REFERÊNCIAS}

ASSOCIAÇÃO BRASILEIRA DE NORMAS TÉCNICAS - ABNT. NBR 10844: Instalações Prediais de Águas Pluviais. Rio de Janeiro, 1989.

ASSOCIAÇÃO BRASILEIRA DE NORMAS TÉCNICAS - ABNT. NBR 15575: Desempenho de Edifícios Residenciais. Rio de Janeiro, 2013.

ASSOCIAÇÃO BRASILEIRA DE NORMAS TÉCNICAS - ABNT. NBR 5626: Instalação predial de água fria. Rio de Janeiro, 1998.

ASSOCIAÇÃO BRASILEIRA DE NORMAS TÉCNICAS - ABNT. NBR 5674: Manutenção de edificações — Requisitos para o sistema de gestão de manutenção. Rio de Janeiro, 2012.

ASSOCIAÇÃO BRASILEIRA DE NORMAS TÉCNICAS - ABNT. NBR 7198: Projeto e Execução de Instalações Prediais de Água Quente. Rio de Janeiro, 1993.

ASSOCIAÇÃO BRASILEIRA DE NORMAS TÉCNICAS - ABNT. NBR 8160: Sistemas Prediais de Esgoto Sanitário: Projeto e Execução. Rio de Janeiro, 1999. 
CARVAlHO JR, Roberto., Patologias em sistemas prediais hidráulico-sanitários. São Paulo, $1^{a}$ edição, Editora Blucher. 2013.

DOLABELA, Gustavo Soares; FERNANDES, Jordane Geraldo Moreira. FALHAS DEVIDO À FALTA DE COMPATIBILIZAÇÃO DE PROJETOS - ESTUDO DE CASOS EM OBRAS DE EDIFICAÇÕES. Revista Pensar Engenharia, [s.1.], v. 1, n. 2, jan. 2014.

GNIPPER, Sérgio Frederico; MIKALDO JUNIOR, Jorge. Patologias freqüentes em sistemas prediais hidráulicosanitários e de gás combustível decorrentes de falhas no processo de produção do projeto. Disponível em: $<$ http://toget.com.br/clientes/ajeci/artigos/Artigo-29\%20Patologias\%20frequentes

\%20em\%20SPHS\%20decorrentes\%20de\%20falhas\%20nosprojetos.pdf>. Acesso em: 30 mar. 2019.

GNIPPER, S. F. et al. Estudo de patologias nos sistemas prediais hidráulicos e sanitários do prédio do ciclo básico II da UNICAMP. RECC - Revista Eletrônica de Engenharia Civil. №2, Vol 1. p. 34-50. 2011.

MACEDO, Noémia Pereira. Estudo de patologias em instalações prediais de abastecimento de água e de drenagem de águas residuais. 2015. 112 f. Dissertação (Mestrado) - Curso de Engenharia Civil, Universidade do Porto, Porto, Portugal, 2015.

VIEIRA, Paulo Cézar Corrêa. Patologias em instalações hidrossanitárias de edifícios residenciais na zona centrosul de Manaus (AM): diagnóstico e terapia. 2016. 118 f. Dissertação (Mestrado) - Curso de Engenharia de Processos, Universidade Federal do Pará, Belém, 2016. 